\title{
Adapting the Systems Model of Performance Management to major changes in the external and internal organisational environments
}

\author{
H.H. Spangenberg* \\ Centre for Leadership Studies (Southern Africa), Graduate School of Business, \\ University of Stellenbosch, PO Box 610, Bellville 7535, Republic of South Africa \\ hspan@usb.sun.ac.za \\ C.C. Theron \\ Department of Industrial Psychology, University of Stellenbosch, \\ Stellenbosch 7600, Republic of South Africa \\ Received October 2000
}

\begin{abstract}
In essence, this article discusses ways to ensure continued relevance of Performance Management in fast-changing environmental and organisational realities. It starts with the rationale for moving from performance appraisal to Performance Management. In view of some persisting problems with regard to Performance Management, a systems approach to help alleviate these problems is discussed. The current status of Performance Management is reviewed, based on international surveys and a recent report on the way Performance Management best-practice organisations utilise the system. In view of this information, the Systems Model of Performance Management is adapted. The paper is concluded with a discussion and recommendations for future research.
\end{abstract}

\section{From performance appraisal to performance management}

By definition, Performance Management generally includes performance planning, i.e. goal setting, ongoing coaching and development of subordinates, formally reviewing performance and rewarding performance. It was first introduced by Michael Beer as an innovative appraisal and development system that combines the developmental facet of performance appraisal with the goal-setting facet of $\mathrm{MBO}$ (Beer \& Ruh, 1976; Beer, Ruh, Dawson, McCaa \& Kavanagh, 1978). At the time it was considered to be an improvement on the performance appraisal system, which was generally considered as subjective and plagued by rater problems. See Table 1 for a comparison of performance appraisal with Performance Management.

Table 1: Comparison of Performance Management with performance appraisal (Adapted from Armstrong and Baron: 1998)

\begin{tabular}{|l|l|l|}
\hline \multicolumn{1}{|c|}{ Characteristics } & \multicolumn{1}{|c|}{ Performance appraisal } & \multicolumn{1}{c|}{ Performance Management } \\
\hline System & Usually tailor made & Tailor made \\
\hline Application & Applied to all staff & Applied to all staff \\
\hline Type of objectives & Individual objectives may be included & $\begin{array}{l}\text { Emphasis on integrating corporate, team and } \\
\text { individual objectives }\end{array}$ \\
\hline Performance measures & Mostly qualitative & $\begin{array}{l}\text { Competence requirements often included as well } \\
\text { as quantified measures }\end{array}$ \\
\hline Frequency & Annual appraisal & $\begin{array}{l}\text { Continuous review with one of more formal } \\
\text { reviews }\end{array}$ \\
\hline Rating system & Top-down system, with ratings & Joint process, ratings less common \\
\hline Link to reward & Often linked to pay & May not be a direct link to pay \\
\hline Adaptability & Monolithic system & Flexible process \\
\hline Paper work & Complex paper work & Documentation often minimised \\
\hline Ownership & Owned by HR department & Owned by line management \\
\hline
\end{tabular}


*To whom all correspondence should be addressed.

In considering the value that could potentially be added by Performance Management, it is important to bear in mind that Performance Management as a process was developed because of the failure of performance appraisals. In essence, Performance Management represents a move from an isolated, mechanistic, HR-driven approach to performance appraisal towards a comprehensive, integrated businessdriven system aiming at organisational and people development. It was believed that by participatively setting goals that are aligned with higher organisational goals, conducting performance reviews and coaching on an ongoing basis, and rewarding an individual's performance based on the outputs of the Performance Management system, desirable outcomes would follow.

\section{A Systems Model of Performance Management}

While conducting a survey among Performance Management facilitators from major South African organisations on potential problems experienced with Performance Management in the early 1990s, a wide range of problems was identified. In fact, so many problems emerged that in collaboration with these Performance Management experts a Systems Model of Performance Management was developed. The reasoning was that a systems approach would be required to address the wide variety of problems at different levels. The Systems Model is described elsewhere in detail (Spangenberg, 1994b). Core elements of the Systems Model are described below. See Figure 1.

The Systems Model comprises inputs, processes, outputs and linkages to other systems. The effectiveness of Performance Management is greatly influenced by inputs into the system. Strategic drivers comprise, firstly, the purpose or purposes of Performance Management. The desired purpose, or purposes, should be determined beforehand, should not contain contradictory elements, and should be clearly communicated to all. Secondly, the transformational framework comprising leadership, corporate strategy and culture is critical to changing the strategic direction of the organisation in order to exploit opportunities in the environment. A fair degree of sophistication is expected from all internal stakeholders, namely management, supervision and employees, to understand and apply the principles and procedures of Performance Management. A productive working relationship with unions or other employee representatives is essential.

Processes comprise the core of the Performance Management system and entail the following:

1. An organisational or unit mission, goals, and strategies are clarified or developed and communicated to all employees.

2. Goals and performance standards, related to wider organisational goals, are negotiated for teams and individuals.

3. Structures are designed or redesigned at organisational, process and team/individual levels to ensure effective functioning of the entire organisation.
4. Performance at organisational, process, team and individual levels is measured, feedback provided on an ongoing basis, and problem-solving mechanisms are in place and used.

5. In addition to ongoing performance reviews, regular performance reviews are scheduled for individual employees. Furthermore, training and development needs are identified and coaching conducted.

Because of the often negative impact of discussing rewards during the final performance review, the reward issue may be separated from the annual review. In the Systems Model it is considered as a linkage to the Performance Management system (Spangenberg, 1994b).

Linkages. Performance Management is normally linked to human resources and occasionally to other organisational systems and processes. With regard to human resources, it is linked to training and development, career management and the reward system. There are an increasing number of productive linkages to business strategy.

Outputs reflect the main purposes of Performance Management, namely implementation of strategy in an efficient manner, with a satisfied employee corps. Short-term outputs comprise overall effective performance, namely meeting the quantity and quality of products or services demanded by the market-place, efficiency, and employee satisfaction and morale. Longer-term outputs entail adaptability and development. Adaptability refers to the extent to which an organisation is capable of responding to external and internal changes. Development in this context refers to ensuring effectiveness over time by investing resources in ways that will enable the organisation to meet future environmental demands. Longer-term outcomes therefore reflect the organisation's approach to environmental change.

\section{Current status of Performance Management}

In order to assess objectively the relevance of the Systems Model in current organisational realities, it is important to look at an assessment of Performance Management as portrayed by field surveys. See Table 1 .

Field studies on Performance Management were conducted in the USA, Great Britain and South Africa. In a comprehensive study by the IPM among 790 public and private organisations in the United Kingdom, no evidence was found that improved organisational performance was related to the operation of a formal Performance Management system (Bevan \& Thompson, 1991). The authors contend, however, that methodological problems might have been the cause of negative results. A significant finding was signs of conflict between two broad Performance Management approaches: the one a 'rewarddriven' approach and the other a 'development-driven' approach. Tension between these two processes may cause both to malfunction, and concern was expressed that the reward-driven strategy would dominate at the expense of the development-driven strategy. 


\begin{tabular}{|c|c|c|c|}
\hline INPUTS & PROCESSES & & OUTPUTS \\
\hline $\begin{array}{l}\text { Strategic drivers } \\
\text { - Corporate strategy } \\
\text { * Purpose Performance } \\
\text { Management } \\
\text { - Leadership } \\
\text { - Culture } \\
\text { - Sense of mission for PM } \\
\text { Purpose and Strategy } \\
\text { * Driving strategy } \\
\text { * Driving culture change } \\
\text { * Driving performance } \\
\text { improvement } \\
\text { Values and Behaviour } \\
\text { * Becoming values driven: } \\
\text { - Participation } \\
\text { - Openness } \\
\text { - Justice and fairness } \\
\text { Internal stakeholders } \\
\text { - Management } \\
\text { - Employees } \\
\text { - Trade Union }\end{array}$ & $\begin{array}{l}\text { - Developing/clarifying } \\
\text { unit mission, goals and } \\
\text { strategy } \\
\text { * Incorporating core } \\
\text { organisational competencies } \\
\text { * Identifying and implementing } \\
\text { individual competencies } \\
\text { - Formulating goals and } \\
\text { creating alignment at } \\
\text { team and individual } \\
\text { level } \\
\text { - Designing and } \\
\text { redesining structures } \\
\text { * Group oriented PM system } \\
\text { - Managing performance } \\
\text { at three levels } \\
\text { - Reviewing performance } \\
\text { Introducing: } \\
\text { * Mastery descriptions } \\
\text { * Behavioural frequency } \\
\text { scales }\end{array}$ & \begin{tabular}{l}
\multicolumn{1}{c}{ LINKAGES } \\
- Business strategy \\
- Balanced scorecard \\
- TQM \\
- HR \\
* Career management \\
* Training and \\
development \\
- Reward System \\
* Linking bonuses to purpose \\
* MM Merit based pay \\
* Utilising multi-level pay \\
system
\end{tabular} & $\begin{array}{l}\text { Short-term } \\
\text { - Production } \\
\text { - Efficiency } \\
\text { - Satisfaction } \\
\text { - Outcomes of } \\
\text { performance review } \\
\text { * Acceptability } \\
\text { Longer-term } \\
\text { - Stabilization of PM } \\
\text { - Organisational } \\
\text { adaptability and } \\
\text { development }\end{array}$ \\
\hline
\end{tabular}

Figure 1: Systems Model of Performance Management (Spangenberg 1994b) - Cursive text indicates 2001 adaptations 
Table 1: Key learning points from Performance Management surveys 1991 - 1998

\begin{tabular}{|c|c|c|c|}
\hline 1991 & 1993-1994 & 1995 & 1997-1998 \\
\hline 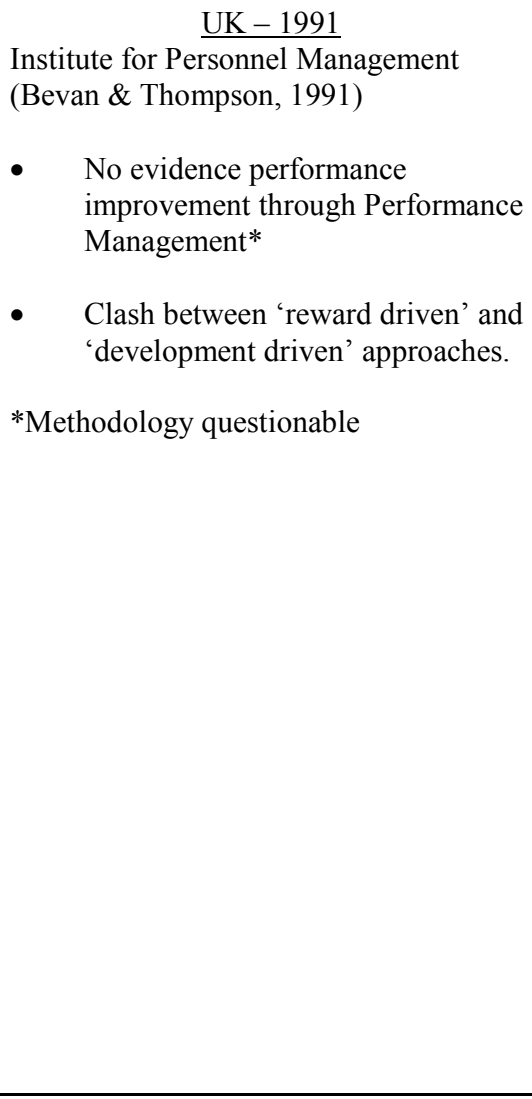 & $\begin{array}{l}\quad \underline{\mathrm{SA}-1993} \\
\begin{array}{l}\text { Graduate School of Business - } \\
\text { University of Stellenbosch } \\
\text { (Spangenberg,1994a) }\end{array} \\
\text { - } \quad \begin{array}{l}\text { Extensive problems across } \\
\text { Performance Management } \\
\text { system }\end{array} \\
\qquad \begin{array}{l}\text { USA - 1993 } \\
\text { (DDI and SHRM, 1994) }\end{array} \\
\text { - Managers getting better at } \\
\text { clarifying goals } \\
\text { * Non managers: } \\
\text { * Not same ownership } \\
\text { Problems coaching, } \\
\text { feedback, reward }\end{array}$ & $\begin{array}{l}\text { (Le Roux, 1995) } \\
\text { - } \quad \begin{array}{l}\text { General positive } \\
\text { attitude }\end{array} \\
\text { - } \quad \begin{array}{l}\text { Dissatisfaction } \\
\text { reward system }\end{array} \\
\text { USA - 1995 } \\
\text { - } \begin{array}{l}\text { Companies with } \\
\text { Performance } \\
\text { Manag) } \\
\text { Management } \\
\text { outperform non- } \\
\text { Performance } \\
\text { Management } \\
\text { companies on key } \\
\text { financial indicators }\end{array}\end{array}$ & 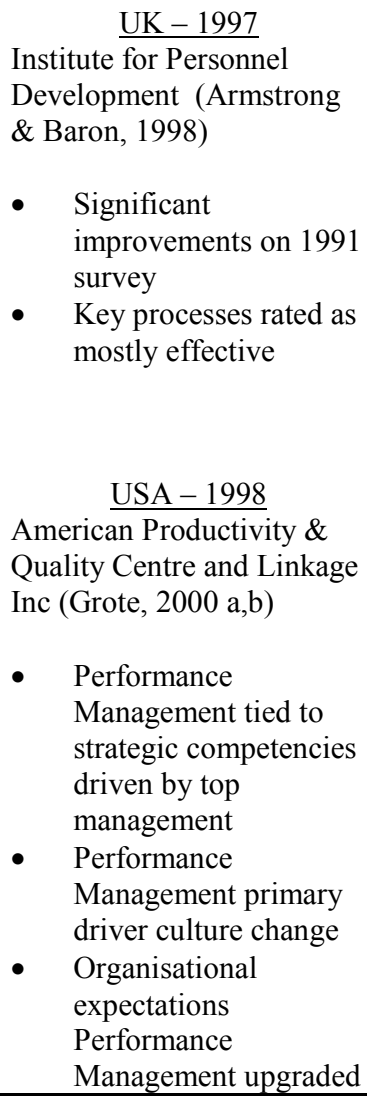 \\
\hline Summary: Negative results & Summary: Variable results & $\begin{array}{l}\text { Summary: Overall, } \\
\text { positive results }\end{array}$ & $\begin{array}{l}\text { Summary: Significant and } \\
\text { strategic improvements }\end{array}$ \\
\hline
\end{tabular}

In 1993 a Performance Management survey was conducted among 374 middle and senior managers from 9 major private companies and utility corporations in South Africa (Spangenberg,1994a). Items were categorised according to an emerging Performance Management Systems Model comprising inputs, processes, outputs and linkages to other systems. The survey indicated extensive problems ranging across the entire Performance Management spectrum. More specifically, 43 of 74 items, i.e. potential problems, were rated as significantly problematic. Particularly disconcerting is the fact that the significantly problematic group included a large number of items that were related to major Performance Management processes such as planning, managing, and reviewing performance. Furthermore, linkages to reward, manpower and career planning, and business planning were problematic. In fact, all seven items dealing with the reward system were rated as significant problems.

A study conducted in the USA in 1993 by Development Dimensions International (DDI) and the Society for Human Resource Management (SHRM) (1994) revealed more positive results. The report claimed that managers were getting better at clarifying goals and objectives and linking them to their organisational business strategies and plans. However, non-managers did not feel the same sense of ownership and involvement in establishing performance plans as did managers. Furthermore, respondents gave the lowest marks for feedback and coaching that:

- they received less frequently than they desired;

- considered as unbalanced regarding their personal strengths and weaknesses; and

- $\quad$ which were broad and unrelated instead of specific and objective.

With regard to outcomes, they indicated significant frustration about the fact that pay and promotion decisions were not clearly linked to the Performance Management system. Dissatisfaction with regard to feedback, coaching and rewarding of performance is in keeping with the South African findings quoted above. In summary, regardless of their position, both management and staff believed there was much room for improvement in Performance Management practices. 
Two studies published in 1995 also painted a more positive picture. Based on data from 437 companies, McDonald and Smith (1995) demonstrated that companies that apply Performance Management outperform companies without such programmes on a wide range of financial and productivity measures. The 205 companies with Performance Management programmes, in contrast to the 232 without these, demonstrated higher profits; better cash flows; stronger share market performance and higher share value; significant gains in financial performance and productivity; higher sales growth; and lower real growth in numbers of employees. In a separate analysis it was found that companies whose performance lagged behind the industry performance, showed significant improvement in their business results after implementing a programme that focused employees' attention on performance and rewards for positive performance. The other study by Le Roux (1995) entailed a Performance Management audit of a South African industrial-commercial company. The audit questionnaire consisted of 102 items categorised according to the Systems Model of Performance Management described in this article. Results indicated that 338 employees (ranging from top management to supervisory and technical staff) in general had a positive attitude towards Performance Management. Negatively rated items were predominantly related to linkage elements of the Systems Model, and more specifically, reflected overall dissatisfaction among employees regarding the linking of Performance Management results to rewards and recognition.

In line with the trend in the USA, a 1997 survey by the British Institute for Personnel and Development (IPD) amongst 562 organisations indicated significant improvements on the 1991 survey in the UK (Armstrong \& Baron, 1998). Key processes were assessed as follows (percentages indicate a combination of 'very effective', and 'mostly effective' assessments): Objective setting and review 75\%; annual appraisal 66\% (59\% 'mostly effective'); self-appraisal 65\%; personal development plans 49\%; and performance-related pay (PRP) $42 \% \quad(36 \%$ 'mostly effective'). A best-practice study in Performance Management was conducted in the USA in 1998 by the American Productivity and Quality Centre (APQC) and Linkage Inc. This comprehensive study utilised an experimental and a control group. Some of the major findings with regard to Performance Management in organisations categorised as best-practice organisations in Performance Management, were as follows (Grote, 2000b): Firstly, in contrast to control group organisations where Performance Management is rarely directly linked to the mission of the organisation, in best-practice organisations independence is replaced by integration. Performance Management elements are directly tied to the organisation's strategic plan. The system is designed to create a visible link between organisational and individual goals, and to reinforce the predetermined core competencies. The development of core competencies is driven by top management and is viewed as a major exercise for providing focus to the entire organisation. Secondly, and of great significance, is that organisational expectations of the Performance Management system have been upgraded. Organisations realise that their Performance Management system has enormous power to transform the organisation's culture. As a matter of fact, one of the major findings of the benchmarking study by Grote (2000b) was that best-practice organisations are using their Performance Management process as the primary driver in forcing cultural change. They are shifting from a best-effort culture to a resultsdriven culture. This results-oriented culture requires that all managers maintain consistent, demanding standards for everyone, and keep raising them. Managers decide exactly what type of performance they want to encourage and what they want to eliminate. They demand that everybody be held accountable for performing like a master. According to Grote (2000b), this new focus on results has placed a new responsibility on Performance Management: the expectation that the system must help strengthen the resolve of the organisation to deal with underperforming employees. In fact, in some organisations Performance Management is used to directly target poor performers for termination.

To summarise, the results from Performance Management surveys in the USA and the UK since 1995 indicate that operational problems with Performance Management have to a large degree been alleviated. In the UK performancerelated pay is still being assessed fairly negatively, but it is encouraging that nearly $60 \%$ of respondents rated the annual appraisal as 'mostly effective'. In contrast, results of the South African surveys are somewhat disappointing with regard to both processes and linkages to other systems, particularly the reward system. Since no Performance Management surveys have been done in South Africa since 1995, it is difficult to judge the current position of the system. Perhaps the main finding of the benchmark study in the USA is that best-practice organisations, private and public, do what they say they do and are prepared to take tough decisions if these are for the good of the larger whole.

\section{Adaptation of the Systems Model}

Democratisation in South Africa in 1994 has led to major transformations in both business and public sector organisations. Like their business counterparts, public sector organisations in South Africa are also pressed for increasing efficiency and effectiveness. Overall, large-scale transformations with their quest for continuous improvement of processes and competitiveness (resulting in flatter organisations with lean staff and wide spans of control) have important implications for organisational systems. At the same time, employees have high expectations of involvement in decision-making processes and the achievement of intrinsic job satisfaction. The uniqueness and self-worth of the individual are acknowledged, and the diversity of people is respected. Labour legislation that protects and promotes the rights of the individual is promulgated.

For organisations to remain competitive in the difficult environment discussed above, superior organisational systems and processes are required. Moreover, serious rethinking is required about the purposes, strategies and operationalisation of Performance Management. The system has to play a proactive role in helping the organisation maintain or increase competitiveness, while at the same time maintaining sound interpersonal relationships. However, to 
be able to play this role the system has to be transformed, to a greater or lesser extent, from its traditional role to a fully effective organisation-oriented system. Some major strategic changes are required to achieve this aim. These changes are: 1. Shifting the purpose of Performance Management from HR orientation to organisation orientation, i.e. driving mission, vision and strategy; driving cultural change, and driving performance improvement of the individual, team and business processes. Furthermore, moving from: 2 . independence to integration; 3 . individual focus to group and process focus; 4. a mechanistic system to a valuesdriven system; and 5. generic competencies to organisationfocused competencies. The above imperatives along with relevant Performance Management literature will be used to adapt the Systems Model.

\section{Inputs}

The strategic drivers of corporate strategy, leadership, and culture remain as important as before. (See Figure 1). A significant phenomenon is the effect of Performance Management's increased involvement in cultural change. The stronger the drives for, e. g. continuous improvement and pay for performance, the stronger the impact thereof on all Performance Management processes. Processes, in turn, influence linkages and outputs. Therefore, the stronger the two initiatives are driven, the stronger the feedback loops from processes, linkages, and outputs back to strategic drivers become. This is particularly true for best-practice organisations where performance-improvement related drives do, in fact, lead to the development of strong performance improvement cultures.

Sense of mission. The strategic driver purpose of Performance Management from the 1994 Systems Model does not seem to be a sufficiently strong force to provide the focus and pull needed for effective implementation of Performance Management. The implications of the new realities discussed above provide an important message to Performance Management: In order to play a leading integrating role in the organisation and serve as a vehicle for tough decisions, there have to be a clear purpose and vision for the system, supported by strong leadership and understood and accepted by all. Indeed, by combining consistent support from the top with a sense of mission for Performance Management, the necessary energy for, and commitment to the system will be stimulated. According to the Ashridge Mission Model (Campbell \& Young, 1991), a sense of mission is achieved when an organisation's purpose, strategy, values and behaviour are aligned. Likewise, to create a sense of mission for an organisational system such as Performance Management, its mission elements must be internally aligned and, importantly, also be aligned to the mission of the organisation. For organisations that plan to implement Performance Management, or to redesign their present system, creation of a mission model may be a very useful first step. The process of developing a mission model will not only stimulate thinking about the true purpose and deliverables of the Performance Management system, but the model will also serve as a mental model throughout the development process, and later serve as an aid for orientation and training.
Sense of mission (purpose and strategy). The directional elements of a mission model for Performance Management, i.e. purpose and strategy, comprise three roles in addition to the traditional Performance Management roles:

1. Driving mission, vision and strategy. Schneier, Shaw and Beatty (1991) state that Performance Management facilitates the execution of business strategy by indicating what to measure (critical success factors), determining appropriate ways of measuring (performance measures), and connecting accountability for performance to these measures. Mohrman and Mohrman (1995) propose that Performance Management practices should all focus on the common goal of running the business. According to Egan (1995), the Performance Management system should focus on those relatively few key (strategic) objectives that will add most value to the business. Egan further contends that if the company or unit has no well-defined strategy, the Performance Management system will be fundamentally flawed. In order to play its rightful strategic role and impact on the wider organisation, Performance Management must move up the organisation and be aligned with leadership. More specifically, it needs to be linked to the leadershipstrategy-culture level as depicted by the Burke-Litwin performance and change model (Burke \& Litwin, 1992; Spangenberg, 1994b). Such a positioning and real support from leadership at the top will pave the way for Performance Management to play the key role in the implementation of strategy. Schneier et al. (1995) propose. It is not surprising, therefore, that best-practice organisations in the USA closely link their Performance Management system to their corporate strategy, mission statement, vision and values. They realise that their Performance Management system is the primary driver for ensuring that their mission, vision, and strategy are achieved (Grote, 2000b).

2. Driving cultural change. A second major objective of Performance Management is the development of a participative, learning and performance-oriented culture. South African Performance Management facilitators strongly emphasise the role of Performance Management as a major instrument in changing organisational culture. McLagan (1993) proposes that Performance Management can be a driving force in creating a participative culture. The role of Performance Management in facilitating cultural change is illustrated by Wellins and Schulz-Murphy's (1995) description of such changes during a reengineering process. Firstly, new value systems, structures and roles translate into new accountabilities and new skills. According to Wellins et al. (1995:37), Performance Management can serve as a driver of the reengineering process because it translates plans into actions and accountabilities, 'helping everyone march to the same beat'. Secondly, and probably more important, a reengineered company requires a new approach to the annual appraisal. For example, the traditional superior-subordinate relationship needs to change. Where people are working with multiple associates inside and outside the organisation, performance evaluation must come from multiple sources. Therefore, the judging role of the leader is replaced by a facilitating role of helping to administer and interpret appraisals. 
According to Grote (2000b), best-practice organisations in the USA now see Performance Management as having great power to transform the culture of the organisation. One way of changing culture is through a growing emphasis on identifying and assessing competencies. People in these companies talk in competency language, and definitions for each competency are clear throughout the company - people know exactly what it takes to get the highest rating. Managing directors argue that a strong push to upgrade human capital is vital. Loyalty and diligence are now taken for granted and continued tenure depends on employees delivering the goods. Both behaviours and results are assessed in Performance Management systems of top-level organisations.

3. Driving performance improvement of the individual, team and business processes. Lane (1994) suggests continuous improvement of employee performance as a major goal of Performance Management. Egan (1995) contends that even well-designed appraisals add value only if they are rooted in a performance improvement process and mindset. Boudreaux (1994) states that top management increasingly realises that the way to achieve sustained organisational improvement is to challenge and empower employee teams to actually implement work improvements on a daily basis. Accepting this as a proven long-term strategy, Boudreaux maintains that once managers see this new paradigm, they will know why the traditional approach to performance appraisal is a failure. Improvement of organisational processes is strongly urged by Rummler and Brache (1990) who, in addition to calling for redesign at organisational, process, team and individual levels, maintain that most scope for improving effectiveness in organisations lies in the improvement of processes.

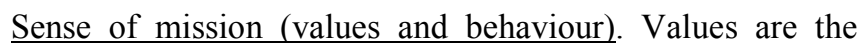
beliefs and moral principles that are inherent in the organisation's culture, and they give meaning to the norms and behaviour standards in the organisation. The interactive nature of Performance Management, combined with its performance-related processes that involve people at all levels, make it an ideal instrument for conveying and institutionalising organisational values. In turn, Performance Management values should reflect and be aligned with organisational values. For example, people orientation should be reflected by meaningful employee participation in the Performance Management process, and an ethical business philosophy should translate into fairness in all dealings with employees, particularly with regard to HR decisions such as pay and promotion. In order to become a dynamic, values-driven system, a good understanding of the values and ethics involved in Performance Management is a necessary first step. These values are participation and involvement, openness, and justice and fairness.

1. Participation entails involvement by management, staff, unions and other stakeholders, from the initiation stage of the Performance Management system up to full implementation and institutionalisation. Research indicates that goals that are set cooperatively lead to trusting relationships and open and constructive discussions of views. Such positive interactive patterns, in turn, are related to motivation, future collaboration and greater acceptance of the Performance Management system (Tjosvold \& Halco, 1992). Cawley, Keeping and Levy (1998) found a strong relationship between participation in performance appraisal and affective reactions such as satisfaction with, and acceptance of the system, perceived fairness of the system, perceived utility of the appraisal, and subordinate motivation to improve after the appraisal. The strong direct relationship between participation and satisfaction confirms earlier research (Dipboye \& dePontbriand, 1981; Giles \& Mossholder, 1990; Kosgaard \& Robertson, 1995; Landy, Barnes \& Murphy, 1978).

2. Openness and specificity of information during goalsetting were researched by Tziner, Kopelman and Livneh (1993) in a study in which they compared Behaviour Observation Scales (BOS) to Graphic Rating Scales. They found that the BOS process produced consistently higher levels of goal clarity, goal acceptance and goal commitment. The performance discussion based on the BOS process enhanced goal clarity by setting goals that were related to specific behaviours, thus pinpointing the precise course of action required to achieve the desired results. The authors suggest that the specificity of the performance review may have led to the acceptance of goals. Also, reviewing progress against specific job-related goals, using a documented performance review process, enhanced commitment to goals. Reviewing research on the effect of specificity on the outcomes of performance appraisal, Tziner, Joanis and Murphy (2000) found evidence that scale formats that focus on specific behaviours could increase both the rater's and ratee's comfortableness with, and acceptance of performance appraisal and feedback. In their own study, they found BOS superior to Behaviourally Anchored Rating Scales (BARS) on all four criteria they investigated, namely goal specificity and observability, ratee perception of goals, and ratee satisfaction.

3. Justice and fairness. Elements of organisational justice, the impact of procedural justice on organisational outcomes, and the impact of a due-process performance appraisal on procedural justice will be reviewed. Organisational justice comprises three elements, namely distributive, procedural, and interactive justice (Bartol, 1999; Flint, 1999; Greenberg, 1990). Distributive justice refers to the outcomes of performance appraisal ratings such as multi-source appraisal, and deals with questions such as desirability of ratings, how ratings compare with those of co-workers, and their acceptability at different organisational levels. Procedural justice, on the other hand, is concerned with the fairness of the process itself. Perceptions of procedural justice impact on the organisation in many ways. In a review of research (Flint, 1999), procedural justice showed a positive association with, for example, performance, organisational commitment, job satisfaction, organisational citizenship behaviour, commitment to organisational decisions, and co-worker monitoring behaviour. Recently, a third kind of justice has been identified, namely interactional justice, which refers to the fairness of the treatment a person receives during the execution of a procedure. Perceptions of interactional justice include factors such as open and honest communications, showing respect and sincerity during discussions, and providing adequate justification for actions (Bies \& Moag, 1986; Moye, Masterson \& Bartol, 1997). 
A due-process appraisal system comprises three characteristics, namely adequate notice, a fair hearing, and judgement based on evidence (Folger, Konovsky \& Cropanzano, 1992; Taylor \& Tracy, 1995). In a quasiexperiment, Taylor and Tracy (1995) found that even though due-process employees received lower ratings than control group members, they displayed more favourable reactions. They were more positive about perceived system fairness, appraisal accuracy, attitudes towards the system, evaluations of managers, and intention to remain with the organisation. Managers also reacted favourably by reporting greater ability to solve work problems, satisfaction with the system, job satisfaction, and less distortion of appraisal results to further their own self-interests. The above study is important in that a due-process appraisal had elicited positive reactions both from employees and managers. In view of the above, a move towards a value-driven Performance Management system seems imperative. Upholding the above values is not only the ethically correct way to operate, but will create a climate conducive to appraisals that will bring about positive outcomes for employees, their superiors, and the organisation as a whole.

The impact of the new organisational realities does not materially alter the relevance of internal stakeholders of management, employees, or labour unions. The increasing number of roles Performance Management has been playing lately, combined with the fact that the system has 'moved up the organisation' will, however, demand a higher degree of knowledge, insight and expertise from managers, employees and labour unions alike. Moreover, the expertise required will be wider than just functional knowledge, and will include a diversity of skills such as the ability to comfortably handle high volumes of electronic data from various sources; identifying, establishing, and rolemodelling key organisational values; handling employee and team performance discussions; and taking tough human resource decisions without contravening new labour legislation. Continuous capacity building will have to be the order of the day.

\section{Processes}

Some significant changes in processes such as developing mission, goals and strategy; designing structures, and reviewing performance are indicated.

Developing/clarifying mission, vision, goals, and strategies. It may be useful for production-oriented companies to incorporate core organisational competencies as part of the broad visioning process. Core competencies comprise technological and production expertise. According to Prahalad and Hamel (1990), it is of major importance for management to consolidate organisation-wide technologies and production exertise into competencies that will empower the organisation to adapt quickly to changing opportunities. One of the significant developments in Performance Management during the past few years has been the incorporation of individual competencies in the Performance Management system. Individual competencies refer to a limited number of critical behaviours, skills, or attributes that all members of the organisation are expected to possess and display. The implication of moving away from generic people competencies towards organisationfocused people competencies is that competencies that are directly related to an individual's work performance, or work unit performance, become part of the Performance Management system. In addition to work-related goals that spell out what has to be achieved, these competencies spell out the behaviours required to perform effectively.

If driven from the top, Performance Management could play a major role in the operationalisation of person-related competencies in different ways (Grote, 2000a). Firstly, it forces top management to determine what really is important for the organisation's success. In the Minnesota Department of Transportation (Mn/DOT), one of the public service best-practice organisations in the USA, a three-step procedure was used for identifying competencies. Firstly, senior management of $\mathrm{Mn} / \mathrm{DOT}$ defined its mission, vision and values in response to an employee survey. Seven core competencies and a number of individual characteristics expected of each employee were also identified as part of that process. Secondly, Performance Management plays a key role in communicating these competencies and ensuring that they are understood. Thirdly, it operationalises the competencies. Significantly, one of the key differences between the best-practice companies and the control group in the APQC/Linkage study was the significantly greater emphasis placed on the identification and assessment of competencies by the top-level companies (Grote, 2000b).

Designing and redesigning structures. In view of the greater involvement of Performance Management in the continuous improvement of core organisational processes, an important strategic issue is the one of individual versus group-oriented Performance Management systems. According to Waldman (1997), traditional Performance Management does not fit well within evolving teamworkoriented strategies, such as Total Quality Management (TQM), which aim to continuously improve efforts to satisfy customers. Deming's (1986) major concern about traditional performance appraisal was, in fact, the preference for a predominantly individual orientation in the attribution, appraising, and rewarding of performance. Along the same lines, Bowman (1999) questions the assumption that individual employees are responsible for outcomes derived from a complex entity such as an organisational system. According to Bowman (1999), a systems perspective holds that the causes of good and bad performance are spread throughout the organisation and its processes. According to Lawler (1994), a team approach to Performance Management is difficult for individuals in the USA to accept because it goes strongly against their supervisor-driven, payfor-performance, individual recognition culture. Lawler acknowledges, however, that such an approach makes particular sense in organisations that rely heavily on selfmanaged work teams. It fits an environment in which teams need to be held accountable for collective performance and results.

With regard to research, Latham, Irvine, Skarlicki and Seigel (1993) are critical of how Performance Management research has tended to neglect the changing nature of the design and structure of modern jobs and groups of jobs. 
Literature about group processes and organisational behaviour provides a considerable number of examples of increasing interrelatedness of positions. In real-world settings work has become interrelated and involves teamwork on the part of individuals. It then follows that a Performance Management system consistent with TQM would take on more of a group-level orientation (Waldman, 1994; 1997). Accordingly, the appraisal and rewarding of a group as a whole can either substitute or supplement individual-level appraisal and rewards, depending upon the specific circumstances.

With regard to the performance review of individuals, one of the biggest challenges for Performance Management implementers is to overcome problems with numeric rating scales. One of the best-practice organisations, Minnesota Department of Transport, has come up with an innovative technique, namely replacing performance definitions with mastery descriptions, and using behavioural frequency scales (Grote, 2000a). Mastery descriptions describe the performance that one might observe in someone who has mastered a specific activity. While challenging to create, mastery descriptions give the appraiser a benchmark against which to compare the actual activities of the individual being assessed. Furthermore, they provide the appraisee with a clear picture of what the organisation expects of him or her. Instead of forcing the rater to make an absolute judgement about the performance of the individual being assessed, behaviour frequency scales ask raters to indicate how frequently the appraisee behaved like a true master. Four categories are used, namely occasionally, sometimes, frequently, and regularly. Further advantages of the behaviour frequency approach are, firstly, that it directly guides performance and, secondly, these behaviour frequency scales elicit less defensive reactions when bad news has to be delivered. Instead of labelling the appraisee, the rater simply states that in a specific area he or she only rarely sees the appraisee doing the things listed. For areas that do not lend themselves to behaviour frequency scales, for example measuring the achievement of goals, they use a five-point scale with 'Fully Successful' as the middle position. Other best-practice companies also try to reduce resistance by coming up with non-threatening scale names. Alcon Laboratories, for example, calls its middle position 'Good Solid Performer' or GSP (Grote, 2000b).

The increasing use of teamwork requires that evaluation of individual performance be complemented by performance evaluation of natural teams. Recently, multiple input sources or $360^{\circ}$ assessment has been emerging as a group or team assessment strategy. This multi-rater approach represents an alternative to obtaining performance information hierarchically, mostly on an individual basis, by a person's direct superior. Multi-rater assessment requires that performance data be obtained from other sources as well, including subordinates, peers, and customers or clients. When teamwork is predominant, peer input would represent a logical source of important performance information. Performance measures may also be largely directed towards customers' inputs, whether they are internal or external customers.

\section{Linkages}

In order to fulfil the new roles described above, Performance Management naturally has to be integrated with major organisational systems. This shift is strongly supported by Bowman (1999) who contends that Performance Management should only be done if it is an integral part of the management system, and helps both the organisation and individual develop to full potential. Driving the implementation of strategy is potentially Performance Management's most important organisational link. Involvement in this key organisational process has, in fact, contributed significantly to upgrade Performance Management from just another HR system to a key organisational system. An emerging related strategic alignment is a closer link between Performance Management and the balanced scorecard. The balanced scorecard provides a balanced set of four measures focusing on finances, customers, internal business processes, and learning and growth, which facilitates implementation of business strategy (Kaplan \& Norton, 1996). A telephonic survey in the Cape Metropolitan area indicated that the balanced scorecard has been used increasingly by major South African organisations in and around Cape Town. Some organisations use the scorecard to break down strategy into the four measurement areas indicated above and apply it at departmental level. Other organisations take the process down to individual employee level. A productive link with Total Quality Management will be beneficial to both systems and the organisation as a whole. A South African organisation with a well-functioning Performance Management system utilises the quality management model of the European Federation of Quality Management (EFQM) to do self-assessment on its management systems.

In contrast to the positive links between Performance Management and other organisational systems discussed above, there is a general concern that the reward system and the way it is applied may be detrimental to Performance Management systems. This observation is particularly true in the South African context (Le Roux, 1995; Spangenberg 1994a). In order to achieve more positive performancereward outcomes, Lawler (1989) makes a few important recommendations. Firstly, Lawler proposes that the annuity feature, whereby merit increases are incorporated in basic salary, leading to salary scales prematurely reaching the ceiling, be eliminated. This will make available enough money to motivate performance by differentiating between the remuneration of good performers and that of less effective performers. A flat job rate should be paid to everyone in a particular position, and a merit bonus range and pool of money be established to raise salaries of some individuals substantially above the job rate. Kerr (1999), who formulated the principle that the best rewards are those that can be taken back if necessary, i.e. reversible rewards, supports Lawler (1989) in proposing the elimination of the annuity feature of merit pay. Reversible pay such as bonuses, incentive pay, or compensation at risk, is consistent with the principle of performance contingency and does not commit an organisation to future payments unless high performance recurs. Secondly, Lawler (1989) proposes that performance bonuses should be related more directly to the purposes of the Performance Management system. This 
may, for example, include implementation of strategy, i.e. contribution to unit or departmental goals and objectives, meeting customer needs and improving organisational processes, as well as the development of self, and others, if required. Thirdly, Lawler (1989) suggests that a multi-level reward system should be implemented. At individual performance level, either merit-based pay or incentive pay may be used to reward employees. Skill-based pay may be added to recognise skill development and utilisation. At team level, gain-sharing plans that lead to work process improvements, which in turn result in higher quality or lower costs, can be utilised. Profit sharing may serve as a third level of reward at times when the organisation is doing well.

\section{Outputs}

An outputs issue that needs consideration is the outcomes of the appraisal-review element of the system. Incorporation of values such as participation, openness, justice and fairness as inputs into the Systems Model may not necessarily lead to favourable outcomes. It is suggested, therefore, that appraisal outcomes, and specifically acceptance (by raters and ratees alike) be incorporated into the Systems Model. Recent research indicates user acceptance or acceptability as a concept that appropriately summarises the ultimate outcomes of performance appraisal (Hedge \& Teachout, 2000).

\section{Discussion}

The most encouraging finding of this review is the fact that during the period of the review, i.e. from 1991-1998, there were steadily improving perceptions of Performance Management, specifically in the USA and the UK. The 1997 UK survey highlighted the significant improvements with regard to the operationalisation of key Performance Management processes. The best practice study in the USA accentuated the upgrading of Performance Management perceptions and expectations. Performance Management is elevated to a more strategic role, particularly with regard to implementation of strategy and cultural change, and importantly, the involvement of top management with implementation of the system. The hands-on role senior executives of a large utility company in the USA played in identifying and implementing people-related competencies is most encouraging.

The improvements to the Systems Model suggested by the literature indicate the way forward for Performance Management. Developing a sense of mission which entails organisation-focused purposes for Performance Management, combined with transforming the system to a participative, open and just system pose very difficult challenges to senior line management and HR specialists alike. While organisation-focused purposes and strategies are imperative to ensure the system's relevance, a valuesdriven Performance Management system, particularly relating to the appraisal-review-decision facet, is essential for enlisting people commitment. A better understanding of the various justice processes, particularly full understanding of due-process appraisal, is crucial for delivering just and fair appraisal outcomes. Over and above legal implications, ethical and business prerogatives demand positive appraisal outcomes. It is reasonable to argue that acceptable appraisal outcomes may create a positive climate for acceptance of the entire Performance Management system.

With regard to processes, the development of core organisational competencies and work-related people competencies may at the same time enhance the organisation's adaptability in a demanding environment, and enable people to perform effectively. The need for Performance Management to adapt to increasing group and team orientation on account of continuous redesign of structures and processes is well-documented in this review. The call on Performance Management researchers to heed the changing nature of modern work design, for example, the interrelatedness of jobs and teams, is indeed timely (Latham et al., 1993). Indications of more frequent use of $360^{\circ}$ performance assessment in group or team situations are a natural extension of the use of multi-rater assessments in areas such as leadership and training and development. The use of mastery descriptions together with behaviour frequency rating scales to circumvent problems with rating inconsistencies encountered with traditional appraisals, may be a viable solution to this problem, provided raters are sufficiently trained. This development is particularly significant in situations where work design prerogatives demand that a large group of employees work on an individual basis, and report to a direct superior.

The most problematic linkage of Performance Management indicated in both the two South African studies and the 1997 UK survey is the performance-reward issue. Although specific organisational conditions may prevail, the careful design and implementation of a merit-based pay system as part of a multi-level remuneration strategy may help to overcome the Achilles heel of Performance Management. It is indeed surprising that multi-level remuneration, and specifically gain sharing, is so blatantly absent in South African reward systems.

With regard to outputs, it is imperative that the system be rid of the negative perceptions about the appraisal element. The appraisal aspect, however, remains an intrinsic part of the Performance Management system. The challenge for practitioners is to design and handle the appraisal aspect in such a way that justified, negative perceptions are alleviated. This may be accomplished by the utilisation of a reasonably bias-free rating method. Only when managers and employees experience trust, satisfaction, and ultimately acceptance of the appraisal element, will Performance Management really flourish.

The extensions to the Systems Model described above have certainly improved the model. However, in order to utilise the Systems Model as a framework for the implementation of Performance Management, a few issues have to be considered. Firstly, one has to measure the effectiveness of an organisaion's current performance appraisal or Performance Management system. This diagnosis will identify the relative strengths and weaknesses of various parts of the total system. In order to do that, it is important to have available a reliable measure of the Systems Model. 
It was for this specific purpose that the Performance Management Audit Questionnaire (PMAQ), based on the Systems Model, was developed (Spangenberg \& Theron, 1997). In the 1997 study, procrustus confirmatory factor analysis showed limited support for the hypothesis that the PMAQ provides a reliable and content-valid measure of the Performance Management construct as conceptualised by the Systems Model. The data set of the 1997 study has since been re-analysed, using Lisrel. The results of this more sophisticated analysis confirm the finding of the original study that the PMAQ does, in fact, provide a reliable and content-valid measure of the Performance Management construct as conceptualised by the Systems Model (Theron \& Spangenberg, 2000). Secondly, some adaptations to the Systems Model discussed above, require that additional items be written for the new elements included in the model. Thirdly, one has to bear in mind that the introduction of a Performance Management system per se will not bring about success overnight. This implies that the system should be applied over a period of time with regular feedback on system performance, e.g. annually. The OD implementation principles of exploration, diagnosis, planning, implementation, evaluation and integration (stabilisation and renewal) are important for the implementation of Performance Management. A strong case can indeed be made out for handling the development, implementation and integration of Performance Management as a major OD intervention (Spangenberg, 1994b).

\section{Recommendations for research}

An investigation into the internal consistency and factor structure of the PMAQ based on the adapted Systems Model would pave the way for the validation of the model.

The evaluation of the validity of the model would, however, require a multi-faceted measure of work unit performance. The Centre for Leadership Studies (Southern Africa) has made considerable progress with developing a Performance Index (PI) that measures unit performance. The validity of the measurement model underlying the PI would, however, first have to be established empirically before proceeding with the validation study.

The somewhat disappointing results of the South African Performance Management surveys, combined with changes in the external environment, in organisations, and in Performance Management itself, necessitate a comprehensive survey on the strengths and weaknesses of Performance Management today. It would be interesting to see to what extent problems highlighted in this review have been eliminated, and to what degree South African organisations apply best practices in Performance Management as discussed above.

Futhermore, empirical research is required on issues such as the degree of integration of the Performance Management system into the organisation, the validity of appraisal instruments currently being used, the incorporation of justice and fairness principles, as well as elements of dueprocess appraisal, and finally, individual/hierarchical versus group-oriented assessment.

\section{References}

Armstrong, M. \& Baron, A. 1998. Performance Management: The new realities. London: Institute of Personnel and Development.

Bartol, K.M. 1999. 'Reframing sales force compersation systems: An agency theory-based Performance Management perspective', Journal of Personal Selling and Sales Management, 19(3):1-16.

Beer, M. \& Ruh, R. 1976. 'Employee growth through Performance Management', Harvard Business Review, 54(4):59-66.

Beer, M., Ruh, R., Dawson, J.A., McCaa, B.B. \& Kavanagh, M.J. 1978. 'A Performance Management system: Research, design, introduction and evaluation', Personnel Psychology, 31(3):505-35.

Bevan, S. \& Thompson, M. 1991 'Performance Management at the crossroads', Personnel Management, 23 November 36-9.

Bies, R.J. \& Moag, J.S. 1986. 'Interactional justice: Communication criteria for fairness', Research on Negotiation in Organisations, 1:43-55.

Boudreaux, G. 1994. 'Response: What TQM says about performance appraisal', Compensation and Benefits Review, 26:20-4.

Bowman, J. S. 1999. 'Performance appraisal: Verisimilitude trumps veracity', Public Personnel Management, 28(4):557-577.

Burke, W.W. \& Litwin, G.H. 1992. 'A causal model of organisational performance and change', Journal of Management, 18(3):523-45.

Campbell, A. \& Young, S. 1991. 'Creating a sense of mission', Long Range Planning, 24(4):10-20.

Cawley, B.D., Keeping. L.M. \& Levy, P. E. 1998. 'Participation in the performance appraisal process and employee reactions: A meta-analytic review of field investigations', Journal of Applied Psychology, 83(4):615-633.

Deming, W.E. 1986. Out of crisis. Cambridge, MA: MIT Institute for Advanced Engineering Studies.

Development Dimensions International (DDI) and Society for Human Resources Management (SHRM). 1994. 'Performance Management: What's hot - what's not', Compensation and Benefits Review, 26 (May-June): 715 .

Dipboye, R.L. \& dePontbriand, R. 1981. 'Correlates of employee reactions of performance appraisals and appraisal systems', Journal of Applied Psychology, 66(2):248-251. 
Egan, G. 1995. 'A clear path to peak performance', People Management, May: 34-7.

Flint, D.H. 1999. 'The role of organisational justice in multisource performance appraisal: Theory-based applications and directions for research', Human Resource Management Review, 9(1):1-20.

Folger, R., Konovsky, M.A. \& Cropanzano, R. 1992. 'A due process metaphor for performance appraisal', Research on Organisational Behaviour, 13:129-177.

Giles, W.F. \& Mossholder, K.W. 1990. 'Employee reactions to contextual and session components of performance appraisal', Journal of Applied Psychology, 75(4):371-7.

Greenberg, J. 1990. 'Organisational justice: Yesterday, today and tomorrow', Journal of Management, 16(2):339-342.

Grote, D. 2000a. 'Public sector organisations: Today's innovative leaders in Performance Management'. Public Personnel Management, 29(1):1-20.

Grote, D. 2000b. 'The secrets of performance appraisal: best practices from the masters', Across the Board, 37(5):519.

Hedge, J.W. \& Teachout, M.S. 2000. 'Exploring the concept of acceptability as a criterion for evaluating performance measures', Group and Organisation Management, 25(1):22-45

Kaplan, R.S. \& Norton, P. 1996. Translating strategy into action: The balanced scorecard. Boston, MA: Harvard Business School Press.

Kerr, S. 1999. 'Organisational rewards: Practical, costneutral alternatives that you may know, but don't practice', Organisational Dynamics, 28(1):61-70.

Kosgaard, M.A. \& Robertson, L. 1995. 'Procedural justice in performance evaluation: The role of instrumental and non-instrumental voice in performance appraisal discussions', Journal of Applied Psychology, 80:657669.

Landy, F.J., Barnes, J. \& Murphy, K. 1978. 'Correlates of perceived accuracy and fairness of performance appraisals', Journal of Applied Psychology, 63(6):751754.

Lane, L.M. 1994. 'Old failures and new opportunities: public sector Performance Management', Review of Public Personnel Administration, Summer: 26-44.

Latham, G.P., Irvine, D., Skarlicki, D. \& Seigel, J.P. 1993. The increasing importance of performance appraisals to employee effectiveness in organisational settings in North America. In C. Cooper \& I. Robertson (Eds.), Review of industrial and organisational psychology. Chichester, England: Wiley, pp.87-132.
Lawler, E.E. 1989. Pay for performance: A strategic analysis. In LR Gomez-Mejia (Ed.), Compensation and Benefits. Washington: The Bureau of National Affairs, Washington, pp.3-136 to 3-181).

Lawler, E.E. 1994. 'Performance Management: The next generation', Compensation and Benefits Review, 26:169.

Le Roux, D.J. 1995. The evaluation of a Performance Management system within South African organisations. MBA thesis, Graduate School of Business, University of Stellenbosch, South Africa.

McDonald, D. \& Smith, A. 1995. 'A proven connection: Performance Management and business results', Compensation and Benefits Review, January - February: 59-64.

McLagan, P.A. 1993. Performance Management: Can it work? St Paul, Minnesota: McLagan International Inc.

Mohrman, A.M. \& Mohrman, S.A. 1995. 'Performance Management is running the business', Compensation and Benefits Review, July-August: 69-75.

Moye, N.A., Masterson, S.S. \& Bartol, K.M. 1997. Differentiating antecedents and consequences of procedural and interactional justice: Empirical evidence in support of separate constructs. Paper presented at the annual meeting of the Academy of Management, Boston: MA.

Prahalad, C.K. \& Hamel, G. 1990. 'The core competencies of the organisation', Harvard Business Review, 68(3):7991.

Rummler, G.A. \& Brache, A.P. 1990. Improving performance. San Francisco: Jossey-Bass.

Schneier, C.E., Shaw, D.G. \& Beatty, R.W. 1991. 'Performance Measurement and Management: A tool for strategy execution', Human Resource Management, 30(3):279-301.

Spangenberg, H.H. 1994a. 'Performance Management: Problems and possible solutions', Journal of Industrial Psychology, 20(1):1-6

Spangenberg, H.H. 1994b. Understanding and implementing Performance Management. Cape Town: Juta.

Spangenberg, H.H. \& Theron, C.C. 1997. 'Developing a Performance Management Audit Questionnaire', South African Journal of Psychology, 27(3):143-150.

Taylor, M.S. \& Tracy, K.B. 1995. 'Due process in performance appraisal: A quasi-experiment in procedural justice', Administrative Science Quarterly, 40(3):495524.

Theron, C.C. \& Spangenberg, H.H. 2000. 'Confirmatory factor analysis of the Performance Management Audit 
Questionnaire', South African Journal of Psychology, 30(4):32-9.

Tjosvold. D. \& Halco, J. A. 1992. 'Performance appraisal of managers: Goal interdependence, ratings, and outcomes', Journal of Social Psychology, 132(5):629-639.

Tziner, A., Kopelman. R.E. \& Livneh, N. 1993. 'Effects of performance appraisal format on perceived goal characteristics, appraisal process satisfaction, and changes in rated job performance: A field experiment', Journal of Psychology, 127(3):281-291.

Tziner, A., Joanis, C. \& Murphy, K.R. 2000. 'A comparison of three methods of appraisal with regard to goal properties, goal perception, and ratee perception', Group and Organisation Management, 25(2):175-191.

Waldman, D. A. 1994. 'Designing performance management systems for total quality implementation', Journal for Oganisational Change Management, 7(2):31-44.

Waldman, D. A. 1997. 'Predictors of employee preferences for multi-rater and group-based performance appraisal', Group and Organisation Management, 22(2):264-288.

Wellins, R.S. \& Schulz- Murphy, J. 1995. 'Reengineering: Plug into the human factor', Training and Development, January: 33-7. 